\title{
Variation in rates of inpatient admissions and lengths of stay experienced by adults with learning disabilities in \\ England
}

\begin{tabular}{|r|l|}
\hline Journal: & Tizard Learning Disability Review \\
\hline Manuscript ID & TLDR-02-2017-0010.R2 \\
\hline Manuscript Type: & Research Feature \\
\hline Keywords: & $\begin{array}{l}\text { Learning disabilities, transforming care, inpatient admissions, health } \\
\text { inequalities, Mental health problems, Intellectual disability }\end{array}$ \\
\hline
\end{tabular}




\section{Variation in Rates of Inpatient Admission and Lengths of Stay Experienced by Adults with Learning Disabilities in England}

\section{Purpose}

Public Health England estimates approximately $2 \%$ of the population of England have learning disabilities, as defined in ICD-10. Less than a quarter of this group (23\%) are, however, identified as having a learning disability by health and welfare systems (Hatton et al., 2016). Previous research has shown that people with learning disabilities do not always receive reasonable adjustments within healthcare, with much of the disparity in health between people with and without learning disabilities accounted for by the greater adversities experienced by people with learning disabilities (Emerson and Hatton, 2013). As a result, people with learning disabilities are over represented in hospital admissions, accounting for $8 \%$ of all inpatient admission stays (NHS England, 2016). An estimated 3000 people were living in specialist inpatient hospitals as of $30^{\text {th }}$ September 2015 (NHS Digital, 2015).

Healthcare policy over the last 25 years in England has consistently aimed to improve the quality of care and support experienced by people with learning disabilities and reduce overreliance on inpatient admissions. The impetus for the most recent policy drive, which has become known as the Transforming Care programme (NHS England, 2015a), was the exposure by the British Broadcasting Corporation in 2011 of institutionalised, wilful neglect and abuse at Winterbourne View Hospital for adults with learning disabilities. Transforming Care (NHS England, 2015a) and associated guidance, especially Building the Right Support (NHSE 2015b), projected that, by March 2019, a minimum of a 35\% reduction could be achieved in the number of specialist inpatient beds commissioned by the NHS in England.

Paragraph 3.13 of Building the Right Support states that "with the right set of services in place in the community, the need for inpatient care will significantly reduce, and commissioners will need to have in place far less hospital capacity." (p.27). Following 
publication of Building the Right Support, the commissioning system in England was reformed by the national commissioning body, NHS England, with 48 local area Transforming Care Partnerships established to deliver on the policy intent. These Partnerships have been developing Transforming Care Plans which have to be approved by NHS England as the national commissioning body. The local area plans should describe how they will change community services to provide an alternative to an inpatient stay in hospital for people with learning disabilities and/or autism who display behaviour which challenges.

There are two key assumptions underpinning Building the Right Support's proposed National Service Model. First, the requirement for risk stratification assumes that, by identifying people who are at risk of seriously challenging behaviour and developing early intervention and preventative support, inpatient admissions can be avoided. Evidence from Lowe et al. (2007) suggests that $10 \%$ of people with learning disabilities, including children and young people in transition, may be at risk of experiencing such behaviour. Second, the National Service Model proposes that, through investing in building alternatives to inpatient units which offer choice of accommodation, access to specialist multi-disciplinary support on an intensive 24/7 basis and reasonable adjustments to universal services, current inpatients can be supported to be discharged.

The present authors sought to analyse the data submitted by commissioners from the 48 Transforming Care Partnerships to (i) analyse rates of inpatient admissions for people with learning disabilities in England (ii) identify factors associated with higher rates of inpatient admission. The authors tested the hypothesis that geographical variations in rates of admission to specialist inpatient services for adults with a learning disability in England are not consistent with variations in prevalence rates for learning disability in the general population. The authors also set out to test the two key assumptions underpinning Building the Right Support: 
1. First, the hypothesis that areas implementing risk stratification resulting in higher rates of people being recorded on Transforming Care Risk Registers would have lower rates of inpatient admissions and shorter lengths of stay in inpatient units.

2. Second, the hypothesis that use of inpatient units by local areas would reflect availability of units and alternative housing support models. This hypothesis was investigated by using the UK House Price Index as a proxy for ease of local provision of accommodation. It was assumed that a negative correlation between the UK House Price Index and inpatient admissions would support the assumption that current service usage was driven in part by service availability and could be altered by the availability of different local options.

\section{Design/Methodology/Approach}

The authors undertook secondary analysis of the 48 financial and activity planning templates submitted by health and social care commissioners to NHS England under the Transforming Care programme.

Procedure

The planning templates were received in response to a request made under the UK Freedom of Information Act 2000 by the parent activist group which at the time of writing was called 7 Days of Action. The planning templates covered returns from local commissioners across all 48 areas identified by NHS England as Transforming Care Partnerships. The 48 Transforming Care Plan areas were grouped by NHS England into 4 Transforming Care regions. The data included rate and number of inpatient admissions by area as of $31^{\text {st }}$ March 2016 and projected levels of inpatient admissions as of $31^{\text {st }}$ March 2019 . The data also included: number of people whose length of stay in inpatient settings was greater than 5 years; number of people who were on local Risk Registers set up under the Transforming Care programme; and the number of former inpatients receiving funded individual aftercare 
and support. The data was categorised on the Transforming Care Planning template using the Royal College of Psychiatrists framework which identifies six categories of specialist inpatient setting in England providing assessment and treatment for people with learning disabilities and/or autistic spectrum disorder (RCP, 2013).

Data to enable calculation of local prevalence rates of learning disability in each Transforming Care Plan area was downloaded from the UK Office for National Statistics (ONS, 2016). Once calculated, the data from each Transforming Care Plan area were normalised to produce: the inpatient admission rate per million people on General Practice registers; the rate at which people were on their local Risk Register; and the rate at which former inpatients received funded individual aftercare and support. One Transforming Care Plan area was identified as an outlier. The analysis was run both including and excluding this data. Inclusion of the data resulted in stronger associations between variables. The decision was taken to report the more conservative findings which excluded the outlier.

Data on the geographical location of settings registered with the Care Quality Commission to provide assessment and treatment for people with learning disabilities was accessed from the CQC database of registered care providers. Data on the UK Housing Price Index (2016) was downloaded from the UK Government Statistical Data Sets.

Analysis

Non-parametric (Spearman's Rho) correlations were performed in SPSS 20 to analyse which factors were associated with higher rates of inpatient admissions and higher numbers of inpatient lengths of stay greater than 5 years across the Transforming Care Areas. One way Analysis of Variance (ANOVA) and Tukey post hoc tests were performed in SPSS 20 on the data from the 4 Transforming Care regions to identify whether there were statistically significant differences between regions.

\section{Findings}


Commissioners reported that 2,510 people with learning disabilities in England were in specialist inpatient services on $31^{\text {st }}$ March 2016 (see Table 1). This was $1 \%$ of people with learning disabilities recorded on General Practice (GP) registers in England. Commissioners reported that 675 people (27\%) had experienced a length of stay in an inpatient setting great than 5 years. The average rate of admissions to inpatient units commissioned by local commissioners (CCGs) was 25 per million general population on GP registers. The average rate of admissions commissioned by national health commissioners (NHS England specialist commissioners) was 28 per million general population on GP registers. 1,180 people $(47 \%)$ were resident in inpatient units commissioned by local health commissioners on $31^{\text {st }}$ March 2016. 1,330 people $(53 \%)$ were resident in settings commissioned by national health commissioners. There was variation observed in the reporting processes followed by commissioners in relation to the level of detail they provided about the types of setting that people were resident in. This information indicated, however, that the most frequently commissioned type of inpatient setting was low secure forensic.

\section{[Table 1 about here]}

Inpatient admission rates varied substantially across Transforming Care Plan areas (see Figure 1). Compared to the average, some areas had very low and some very high inpatient admission rates. A similar variation was found in terms of the number of people whose length of stay in inpatient units was greater than five years.

\section{[Figure 1 about here]}

Inpatient admission rates were found to be positively correlated with the rate of people being on Transforming Care risk registers $(r h o=0.42, n=47, p<0.003$ ) and the number of inpatient units registered to provide assessment and treatment in the Transforming Care Plan area (rho=0.42, $n=47, p<0.003$ ) (see Table 2). Inpatient admission rates were found to be negatively correlated with the UK House Price Index (rho=0.51, n=47, $p<0.01)$. 
The number of people experiencing inpatient lengths of stay greater than five years was found to be positively correlated with the number of inpatient units registered to provide assessment and treatment in the Transforming Care Plan area (rho=0.50, $n=47, p<0.01)$.

\section{[Insert Table 2 about here]}

Differences across the 4 NHS England Transforming Care regions were also investigated. The 4 regions, as defined by NHS England, were North, Midlands \& East, South and London. There were statistically significant differences between the 4 regions as determined by one-way Analysis of Variance (ANOVA) for: rate of inpatient admissions $(F=10.04, \mathrm{df}=3$, $43, p<0.001)$; the number of people whose inpatient length of stay was greater than 5 years $(F=7.31, d f=3,43, p<0.001)$; the UK House Price Index $(F=11.99, d f=3,43, p<0.001)$; and the rate of people on Risk Registers $(F=25.20, d f=3,43, p<0.001)$. There was no statistically significant difference between the 4 Transforming Care Plan regions for: the number of inpatient settings registered to provide assessment and treatment $(F=1.86, d f=3,43$, $p=0.15)$; and the rate of former inpatients receiving funded aftercare support $(F=0.97, d f=3$, 43, $p=0.42)$.

Tukey post hoc tests revealed statistically significant regional differences in rates of inpatient admission. Specifically, the South region had a lower rate than the North region $(p<0.001)$ and the Midlands \& East region $(p<0.002)$. Statistically significant differences were also observed between regions in the number of people with a length of stay greater than five years in an inpatient setting. The North region had higher numbers than Midlands \& East $(p<0.002)$, the South region $(p<0.003)$ and London $(p<0.035)$. 


\section{Discussion}

Our analyses are consistent with the hypothesis that variations in the admission rate of people with learning disabilities to specialist inpatient units do not simply reflect local prevalence rates for learning disability. Our findings indicate that people with learning disabilities are at risk of higher rate of inpatient admission in areas where there are higher numbers of inpatient settings which provide assessment and treatment for people with learning disabilities. The findings add to the existing body of knowledge about health inequalities faced by people with learning disability in five main ways.

Firstly, this is the first study to examine the data that commissioners in England have reported to NHS England on specialist inpatient admissions of people with learning disabilities and to report on the possible factors related to higher rates of inpatient admission. These data do have limitations. In particular as data were collected from commissioners at the start of the Transforming Care process it is not yet possible to make any observations about longitudinal trends. Also, the data do not distinguish between new admissions and re-admissions.

Secondly, in contradiction to the assumptions in Building the Right Support and the National Service Model, the findings indicate that, in local Transforming Care partnership areas where risk stratification results in higher rates of people with learning disabilities being registered on local Risk Registers, there are higher rates of inpatient admissions. This indicates that there are more complex, contextual issues at play that would benefit from further research.

Thirdly, local Transforming Care partnership areas where there was greater availability of and access to assessment and treatment units were associated with higher rates of inpatient admissions and long lengths of stay. These findings appear to be consistent with the assumptions in the National Service Model that propose the building of alternatives to 
inpatient units should impact positively on the numbers of people who are able to live independent lives outside of specialist units.

Fourthly, the findings indicated that low forensic beds were the most frequently used type of inpatient bed by commissioners. The finding appears to be consistent with that of Glover and Brown (1996) who observed that 31 per cent of psychiatric inpatients with intellectual disability or autism were detained on a court order. However, this finding must be treated with caution as the relevant data reported by commissioners was incomplete on some returns.

Finally, the variation observed in the rate of inpatient admissions across Transforming Care areas and the number of people who are experiencing inpatient length of stays greater than five years is not simply explained by the variations in the rate of prevalence of learning disability across local areas. Far more learning disabled people were admitted to specialist hospitals (relative to prevalence) in some local Transforming Care partnership areas than others. It should be acknowledged that explanation of this variation is somewhat speculative. There were, however, significant associations with the availability of local assessment and treatment units and with the cost of housing as measured by the UK House Price Index. The correlation between low house prices and higher rates of admission may suggest that assessment and treatment units have been located in places where there are low house prices. A simple explanation to the correlation may be that local commissioners may be more inclined to commission a placement in these areas where they have ease of access to a local facility. However, there is also some evidence that prevalence of challenging behaviour is higher in areas of relative deprivation. These tend to be areas which are also likely to have lower house prices. McGill \& Toogood (1994) argued that there is an environmental context to challenging behaviour. Assessment and treatment units may then have been built in areas where there has, historically, been higher levels of demand for services for people more likely to exhibit challenging behaviour. The findings may also suggest that the development of specialist inpatient provision for people with learning 
disabilities has been shaped by economic factors such as the cost of developing and running provision based on local housing market prices. Irrespective of the reason, the uneven spread of provision has led to the development of an effective "market" of people with a learning disability. Such observations would be consistent with the findings of Glover and Olsen (2012) who noted the extent to which Strategic Health Authorities "imported" or “exported” people across England.

In conclusion, greater attention should be given to understanding the socio-economic and cultural aspects driving inpatient admission rates to more fully understand how to reduce such rates and increase the use of alternative support options.

\section{Acknowledgements}

The findings and views reported in this paper are those of the authors and should not be attributed to any other agency. The authors wish to note our thanks to the families involved in the 7 Days of Action Campaign and the development of My Own Front Door for their trust in sharing data they collected with us.

\section{References}

Emerson, E. and Hatton, C. (2013), Health Inequalities and People with Learning Disabilities, Cambridge University Press, Cambridge, UK.

Glover G. and Brown I. (1996), "People with intellectual disabilities hospitalised by courts in England", Tizard Learning Disability Review, Vol. 20 No. 1, pp. 41-47.

Glover G. and Olsen V. (2012), "Assessment and treatment units and other specialist inpatient care for people with learning disabilities in the Count-Me-In surveys, 2006 to 2010", available at 
http://www.improvinghealthandlives.org.uk/uploads/doc/vid 17542 IHAL\%202012-

09\%20A\&T\%20and $\% 20$ other $\% 20$ specialist $\% 20$ inpatient $\% 20$ care $\% 20$ for $\% 20$ people $\% 20$ with \%20LD\%20in\%20the $\% 20$ Count-Me-In\%20Census.pdf

Hatton C., Glover G., Emerson E. and Brown I. (2016), People with Learning Disabilities in England 2015, Public Health England, London.

Lowe, K., Allen, D., Jones, E., Brophy, S., Moore, K. and James, W. (2007), “Challenging behaviours: prevalence and topographies", Journal of Intellectual Disability Research, Vol. 51, No. 8, pp. 625-636.

McGill, P. \& Toogood, S. (1994), “Organising community placements”, Emerson, E., McGill, P. and Mansell,J. (Eds.) Severe Learning Disabilities and Challenging Behaviours, Chapman and Hall, London.

NHS Digital (2015), "Learning disability census”, available at http://content.digital.nhs.uk/ldcensus (accessed 7 December 2016).

NHS England (2015a), "Transforming Care”, available at http://www.england.nhs.uk/ourwork/qual-clin-lead/ld/transform-care/ (accessed 7 December 2016).

NHS England (2015b), "Building the Right Support: a national plan to develop community services and close inpatient facilities for people with a learning disability and/or autism who display behaviour that challenges, including those with a mental health condition", available at https://www.england.nhs.uk/wp-content/uploads/2015/10/ld-nat-imp-plan-oct15.pdf (accessed 5 January 2017).

NHS England (2016), "Bed availability and occupancy data - overnight", available at https://www.england.nhs.uk/statistics/statistical-work-areas/bed-availability-andoccupancy/bed-data-overnight/ (accessed 20 January 2017). 
ONS (2016), “Clinical Commissioning Group mid-year population estimates”, available at https://www.ons.gov.uk/peoplepopulationandcommunity/populationandmigration/populatione stimates/datasets/clinicalcommissioninggroupmidyearpopulationestimates (accessed 20 January 2017).

Royal College of Psychiatrists (2013), "People with learning disability and mental health, behavioural or forensic problems: the role of in-patient services" available at http://www.rcpsych.ac.uk/pdf/FR\%20ID\%2003\%20for\%20website.pdf (accessed 20 January 2017).

UK House Price Index data published by Land Registry (C) Crown copyright 2016 - April 2016 Release Date 14 June 2016, updated 5 July 2016 https://www.gov.uk/government/statistical-data-sets/uk-house-price-index-data-downloadsapril-2016 (accessed 2 February 2017). 


\section{Tables}

Table 1: Average inpatient admission rate and other characteristics of Transforming Care Partnerships

\begin{tabular}{|l|c|c|c|c|c|c|}
\hline & $\begin{array}{c}\text { Inpatient rate } \\
\text { per million } \\
\text { GP } \\
\text { population } \\
\mathbf{3 1 . 0 3 . 2 0 1 6}\end{array}$ & $\begin{array}{c}\text { Number of } \\
\text { inpatients } \\
\text { with length } \\
\text { of stay >5yrs }\end{array}$ & $\begin{array}{c}\text { Number } \\
\text { CQC } \\
\text { registered } \\
\text { inpatient } \\
\text { settings }\end{array}$ & $\begin{array}{c}\text { UK House } \\
\text { Price Index } \\
\mathbf{0 1 . 0 4 . 2 0 1 6}\end{array}$ & $\begin{array}{c}\text { Rate per } \\
\text { million } \\
\text { people on } \\
\text { Risk } \\
\text { Registers }\end{array}$ & $\begin{array}{c}\text { Rate per } \\
\text { million } \\
\text { former } \\
\text { inpatients } \\
\text { with funded } \\
\text { support }\end{array}$ \\
\hline $\boldsymbol{N}$ Valid & 47 & 47 & 47 & 47 & 47 & 47 \\
\hline Mean & 53.15 & 14.36 & 5.72 & 110.04 & 385.5 & 93.72 \\
\hline Median & 55 & 10 & 5 & 109 & 106 & 64 \\
\hline
\end{tabular}

Table 2: Associations between inpatient admission rate and other characteristics of Transforming Care Partnerships

\begin{tabular}{|l|c|c|c|}
\hline & $\boldsymbol{N}$ & $\begin{array}{c}\text { Correlation } \\
\text { (Spearman's Rho) }\end{array}$ & Significance \\
\hline $\begin{array}{l}\text { Number of inpatients } \\
\text { with length of stay } \\
>5 \text { yrs }\end{array}$ & 47 & 0.63 & $\mathrm{P}<0.001$ \\
\hline $\begin{array}{l}\text { Number CQC } \\
\text { registered inpatient } \\
\text { settings }\end{array}$ & 47 & 0.42 & $\mathrm{P}=0.003$ \\
\hline $\begin{array}{l}\text { UK House Price Index } \\
\text { 01.04.2016 }\end{array}$ & 47 & -0.51 & $\mathrm{P}<0.001$ \\
\hline $\begin{array}{l}\text { Rate per million } \\
\text { people on Risk } \\
\text { Registers }\end{array}$ & 47 & 0.42 & $\mathrm{P}=0.003$ \\
\hline $\begin{array}{l}\text { Rate per million } \\
\text { former inpatients } \\
\text { with funded support }\end{array}$ & 47 & 0.00 & Not significant \\
\hline
\end{tabular}




\section{Figures}

Figure 1: Variation in the rate of inpatient admission across Transforming Care Partnerships

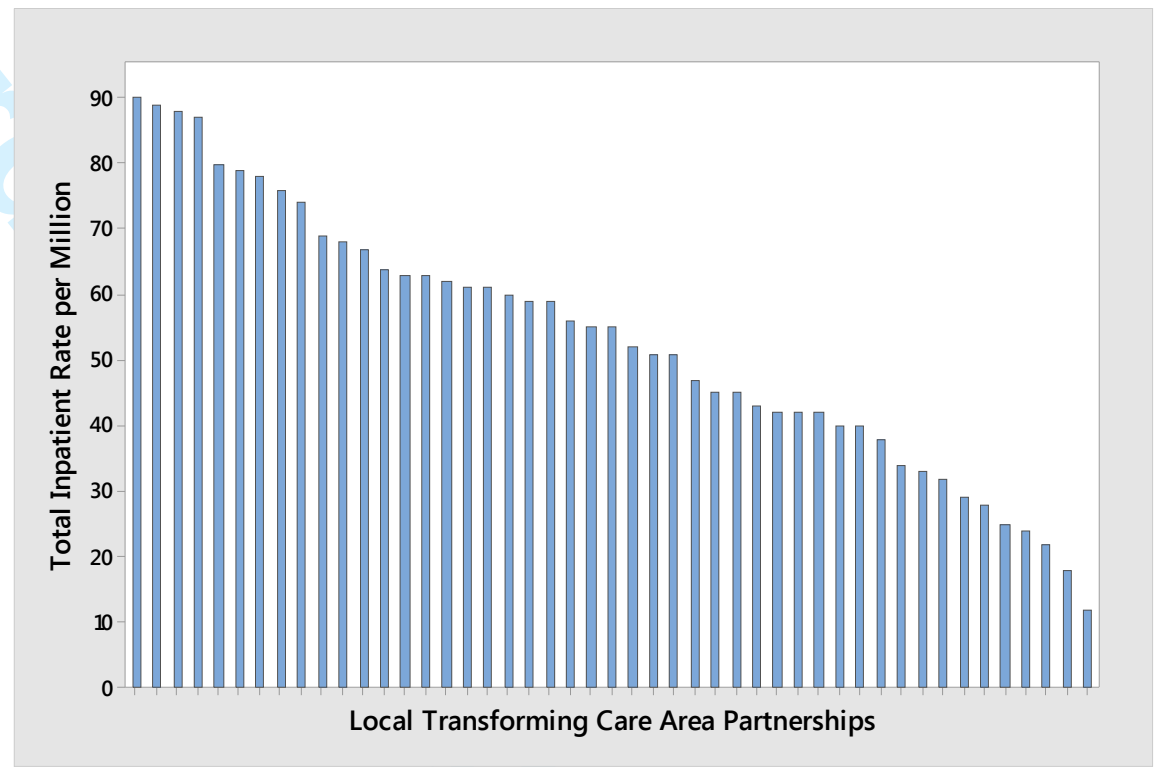

29

30

31

32

33

34

35

36

37

38

39

40

41

42

43

44

45

46

47

48

49

50

51

52

53

54

55

56

57

58

59

60 